7

\title{
Western Australian students' alcohol consumption and expenditure intentions for
}

\section{Schoolies}

Full citation: Jongenelis, M., Biagioni, N., Hagger, M. S., \& Pettigrew, S. (in press). Western Australian students' alcohol consumption and expenditure intentions for Schoolies. Australian Journal of Primary Health. doi: 10.1071/PY16104

RUNNING HEAD: Students' alcohol consumption intentions for Schoolies Abstract

Issue addressed: In Australia, the immediate post-school period (known as 'Schoolies') is associated with heavy drinking and high levels of alcohol-related harm. This study investigated students' intended alcohol consumption during Schoolies to inform interventions to reduce alcohol-related harm among this group.

Methods: An online survey was administered to students in their senior year of schooling. Included items related to intended daily alcohol consumption during Schoolies, amount of money intended to be spent on alcohol over the Schoolies period, and past drinking behaviour.

Results: On average, participants $(n=187)$ anticipated that they would consume eight standard drinks per day, which is substantially higher than the recommended maximum of no more than four drinks on a single occasion. Participants intended to spend an average of $\$ 131$ on alcohol over the Schoolies period.

Conclusions: Although higher than national guidelines, intended alcohol consumption was considerably lower than has been previously documented during Schoolies events. The substantial amounts of money expected to be spent during Schoolies suggest this group has adequate spending power to constitute an attractive target market for those offering alternative activities that are associated with lower levels of alcohol-related harm. 
1 What is known about the topic?

2

3

4

5

6 What does this paper add?

7

8

9

10

11

10

- Schoolies celebrations often involve excessive alcohol consumption. Many of those participating in these celebrations experience alcohol-related harm, making minimisation of this harm a public health priority.

- This study highlights the importance of identifying changes that could be made to the Schoolies environment to reduce expenditure on alcohol and increase expenditure on alternative activities that do not involve excessive alcohol consumption. 
2

\section{Introduction}

The celebrations undertaken in the period immediately after completion of high school are a distinct marker of the transition from childhood to adulthood in Australia (Pettigrew et al., 2016). Students about to complete their secondary school studies are colloquially referred to as 'leavers' and the immediate post-school celebration period is known as 'Schoolies' (Hutton et al., 2015; Midford et al., 2007; Pettigrew et al., 2015). During Schoolies, many Australian leavers congregate in large numbers at favoured holiday destinations that are typically some distance from home (Irwin et al., 2015). These celebrations are approximately four days in duration and provide leavers with much sought after autonomy from parents and other authority figures (Midford et al., 2007; Pettigrew et al., 2015).

Schoolies celebrations often involve excessive alcohol consumption (Hutton, Roderick et al., 2012; Lubman et al., 2014; Midford et al., 2007; Pettigrew et al., 2015). Numerous Australian studies have found that leavers consider alcohol to be a necessary and highly enjoyable aspect of the Schoolies experience (Midford et al., 2007; Midford et al., 2004; Pettigrew et al., 2015, 2016). In particular, these studies document (i) the perceived role of alcohol in marking the end of childhood and formal schooling and (ii) an explicit intention among many leavers to achieve advanced states of inebriation. A recent South Australian study found that previous Schoolies attendees reported spending the majority of their celebration planning time preparing for the type of alcohol they would consume, how they would purchase alcohol before attending Schoolies, and making sure they had sufficient money for the event (Hutton et al., 2015).

Despite many leavers being below the age of 18 (the legal age to purchase alcohol in Australia), previous studies have documented the excessive quantities of alcohol that are typically consumed by those attending Schoolies celebrations (Lam et al., 2014; Lubman et al., 2014; Salom et al., 2011). For example, Lam et al. (2014) found that male leavers at a Schoolies celebration location in Western Australia consumed an average of 18 standard drinks per day and their female counterparts consumed 13 drinks per day. This study found that many of the participants experienced alcohol-related harm in the form of vomiting, blackouts, accidents and injuries, and unprotected sex. These harms make excessive drinking during Schoolies a significant public health issue (Hutton, Cusack et al., 2012). 
In recent years there have been calls for research to inform health promotion strategies focusing on alternative end-of-school celebratory experiences to reduce the emphasis on alcohol during these celebrations (Howat et al., 2013; Pettigrew et al., 2015, 2016). Little is currently known about alternative activities that may be considered appropriate and attractive to leavers, highlighting the need for research to begin to identify viable options that have minimal alcohol involvement (Pettigrew et al., 2015). An important first step in this process is understanding the monetary investment that leavers are willing to make to facilitate their Schoolies celebrations to provide insight into the financial feasibility of alternative celebratory options. Ideally, this would involve gathering information relating to students' total planned Schoolies-related expenditure and the amounts they intend to spend on alcohol in particular. This information could provide an indication of the relative importance of alcohol in leavers' anticipated experiences and identify the potential for students to afford other celebratory experiences that have lower levels of alcohol-related risk.

Accordingly, the aim of the present study was to assess intended daily alcohol consumption and anticipated alcohol-related expenditure during Schoolies among a sample of Western Australian school leavers. Given previously identified differences in alcohol consumption between males and females during Schoolies (Lam et al., 2014; Lubman et al., 2014), whether alcohol consumption and expected expenditure varied by gender was also of interest.

\section{Method}

The study received ethics approval from a University Human Research Ethics Committee. In the lead up to the 2014 Schoolies period, ten schools from a diverse range of areas across Western Australia were invited to share a link to an online survey with their senior students. The survey link was also placed on two websites that provided Schoolies information for leavers (e.g., tips for managing the Schoolies period, information relating to what to expect, accommodation options). Given the varying means by which the survey link was disseminated, response rates could not be estimated.

The survey instrument was developed based on the extant literature relating to leavers' motives and behaviours (Hutton et al., 2010; Lam et al., 2014; Pettigrew et al., 2015). The survey included open response items related to intended daily alcohol consumption during 
1 Schoolies (On average, how many standard drinks of alcohol per day do you think you will

2 drink during Leavers?) and the total amount of money participants intended to spend in total

3 and on alcohol during Schoolies (How much money do you think you (and/or your parents)

4 will spend on Leavers in total - including transport, accommodation, activities, food and

5 drinks? and How much money, if any, do you think you (and/or your parents) will spend just

6 on alcohol for Leavers?). A scaled response item assessed previous binge drinking behaviour

7 (How often do you consume more than four standard drinks on a single drinking occasion; 7

8 response options ranging from "never" to " $5+$ days a week"). Self-reported items assessing demographic variables (age, gender, family income) were also included. To facilitate accurate measurement of intake, a figure sourced from the National Health and Medical Research Council (NHMRC, 2009) depicting numerous types of beverages in standard drink quantities was presented to respondents. Reflecting the current Australian national alcohol guideline relating to risk of short-term harm (NHMRC, 2009), an "intention to binge drink" dummy variable was also created that distinguished between those who intended to consume more than four standard drinks per day during Schoolies and those who did not.

Descriptive analyses were conducted to explore intended alcohol consumption and intended financial expenditure during Schoolies. Independent samples $t$-tests were conducted to assess for gender differences on the continuous variables under investigation. Pearson chi-square tests were conducted to assess for gender differences on the categorical variables under investigation. Marginal homogeneity tests were conducted to assess for differences in previous binge drinking behaviours and Schoolies binge drinking intentions. SPSS 24 was used for all analyses. A $p$ value $<.05$ was used to determine significance.

\section{Results}

In total, 187 usable responses were received. Nearly two-thirds $(62 \%)$ of the sample was female. Scores greater than three standard deviations from the mean were deemed to be outliers. These scores were assigned the mean plus three standard deviations value (as per Mastroleo et al., 2014; Voogt et al., 2013).

Descriptive statistics for intended alcohol consumption, binge intentions, previous binge drinking behaviour, and planned expenditure are presented in Table 1. Nearly a quarter (23\%) of the sample reported that they intended to abstain from alcohol consumption altogether 
during the Schoolies period. Across the entire sample (including intended abstainers), the average intended number of standard drinks was eight, with males intending to drink significantly larger daily amounts than females (12 vs 6 standard drinks respectively: $(t(91.99)=2.87, p=.005, d=0.49)$. Just over half of the respondents reported intending to drink more than four drinks per day (i.e., binge drink), while $21 \%$ reported intending to drink at levels below this threshold. Males were significantly more likely to report both intending to binge drink during Schoolies $\left(\chi^{2}(1)=3.96, p=.047, \phi=.15\right)$ and binge drinking at least once per month prior to Schoolies $\left(\chi^{2}(1)=12.41, p<.001, \phi=.26\right)$. The difference between previous binge drinking behaviour and intended binge drinking behaviour at Schoolies was significantly greater in females, with prevalence increasing from $33 \%$ to $50 \%$ ( $p=.003$ ).

On average, respondents reported planning to spend $\$ 965$ during the Schoolies period, with no significant gender difference in planned expenditure. Of the total amount, 14\% (\$131) was intended to be spent on alcohol alone, with males expecting to spend considerably more on alcohol than females $(\$ 1011$ vs $\$ 938 ; t(114.21)=2.00, p=.048, d=0.32)$.

\section{Insert Table 1 about here}

\section{Discussion}

The average level of intended alcohol consumption reported by students in the current sample, approximately eight standard drinks per day, is double the NHMRC guideline of "no more than four standard drinks on a single occasion" (NHMRC, 2009). However, it is considerably lower than previously documented consumption rates during Schoolies, with Lam et al. (2014) reporting an average of 16 standard drinks per day at a Western Australian celebration location. This difference between drinking intentions found in the present study and actual behaviours reported during previous Schoolies celebrations suggests that consumption rates may be higher than intended once leavers find themselves in high-alcohol environments. Contributing factors may be peer pressure overcoming personal preferences and the desire to act in accordance with others in social contexts (Hutton, Cusack et al., 2012).

Consistent with previous research indicating that males in this age group consume more alcohol than their female counterparts (Australian Institute of Health and Welfare, 2014; 
Iwamoto \& Smiler, 2013), males in the present study reported intending to drink significantly larger quantities of alcohol during Schoolies and demonstrated a significantly higher prevalence of binge drinking prior to Schoolies compared to females. However, while females reported more modest intentions and past drinking behaviours, the difference between time periods was significantly and substantially larger, indicating that Schoolies is likely to represent a dramatic escalation in their alcohol intake relative to their previous drinking behaviours. By comparison, there was no significant difference in the proportion of males who reported binge drinking at least monthly prior to Schoolies and the proportion of those intending to binge drink during Schoolies. These results indicate that both male and female leavers should be primary targets of interventions designed to reduce alcohol-related harm during Schoolies - males because of their overall high intake levels and females because of the likelihood of a sudden escalation of their drinking behaviours.

A novel aspect of this study was the examination of students' planned expenditure for the Schoolies period. Respondents indicated they would spend nearly $\$ 1000$ on Schoolies in total and $\$ 130$ on alcohol specifically. This expected expenditure on alcohol needs to be interpreted in the context of the low per unit cost of alcohol in Australia and provides support for the introduction of measures that may be effective in increasing the cost of alcohol, particularly strength-based measures such as minimum pricing. Increasing the cost of the cheapest alcohol products may exert downward pressure on overall intake levels during events such as Schoolies given the previously identified tendency of leavers to plan their drinking around the relative cost of different alcoholic beverages to maximise their alcohol consumption within their budgets (Hutton et al., 2015).

When aggregated across the cohort, total expected expenditure over the Schoolies period is a substantial amount of money that could be channelled into other activities that achieve similar social bonding, relaxation, and celebration outcomes but do not involve such high levels of alcohol-related risk. It has been proposed that efforts to develop and promote such alternative activities and minimise harm should be undertaken by, or in collaboration with, members of the target audience to minimise the perceived influence of the authority figures from whom leavers are attempting to distance themselves (Hutton, Cusack et al., 2012; Pettigrew et al., 2016). This may help to improve perceptions of these alternative activities relative to those involving excessive alcohol consumption. 
1 The present study has limitations to be considered in future research on this topic. First, the intention-behaviour gap (Hagger et al., 2016; Mullan et al., 2011) means that respondents' intended alcohol consumption may not align with actual intake. This is evident in the substantial differences between leavers' intended consumption behaviours in the present study and their actual consumption when attending celebration events (Lam et al., 2014; Lubman et al., 2014; Salom et al., 2011). Longitudinal studies could be undertaken to track students pre- to post-Schoolies to investigate the extent to which intentions translate into behaviours and identify factors that influence whether intentions are exceeded. Such research would be useful in explicating the range of individual, social, and environmental factors that cause young people to consume excessive quantities of alcohol during such events. Second, as has been the case for previous research on Schoolies (Hutton et al., 2010, 2015; Hutton, Roderick et al., 2012; Lam et al., 2014; Lubman et al., 2014; Midford et al., 2007; Pettigrew et al., 2015, 2016), the results of the present study pertain to only one Australian state. National studies that include larger samples of students from across the country would provide a more representative and comprehensive picture of the Schoolies phenomenon.

An important finding of the present study was that $23 \%$ of the sample intended to abstain from alcohol consumption completely during Schoolies. This is an important area of further research because of the potential for insights into potentially attractive alternative activities. Future studies could explore motivations and intentions among this group and identify specific activities that may represent realistic options for leavers.

\section{Conclusion}

The present study highlights the importance of reducing the salience of alcohol during Schoolies and redirecting leavers to alternative activities that are associated with lower levels of alcohol-related harm. The school leavers who participated in this study reported planning to spend a substantial amount of money during their Schoolies celebrations. Working with leavers to design, implement, and promote alternative celebratory activities that do not involve excessive alcohol consumption may reduce current high rates of alcohol-related harm and the burden placed on primary care settings during this period. 


\section{References}

Australian Institute of Health and Welfare. (2014). National Drug Strategy Household Survey 2013: Alcohol chapter - Online data tables. Retrieved from http://www.aihw.gov.au/publication-detail/?id=60129549469.

Hagger, M. S., Luszczynska, A., de Wit, J., Benyamini, Y., Burkert, S., Chamberland, P.-E., \& Gollwitzer, P. M. (2016). Implementation intention and planning interventions in health psychology: Recommendations from the Synergy expert group for research and practice. Psychology \& Health, 31, 814-839. doi:10.1080/08870446.2016.1146719.

Howat, P., Jancey, J., \& Binns, C. (2013). Are there more positive alternative celebration opportunities to Schoolies week? Health Promotion Journal of Australia, 24(3), 161162.

Hutton, A., Cusack, L., \& Zannettino, L. (2012). Building public policy to support young people in reducing alcohol-related harm when partying at Schoolies Festivals. Australian Journal of Primary Health, 18, 96-100.

Hutton, A., Cusack, L., Zannettino, L., Shaefer, S. J. M., Verdonk, N., \& Arbon, P. (2015). What are school leavers' priorities for festival preparation? Australian Journal of Primary Health, 21, 249-253.

Hutton, A., Munt, R., Zeitz, K., Cusack, L., Kako, M., \& Arbon, P. (2010). Piloting a mass gathering conceptual framework at an Adelaide Schoolies festival. Collegian, 17(4), 183-191.

Hutton, A., Roderick, A., Munt, R., Mayner, L., Kako, M., \& Arbon, P. (2012). Celebrating the end of school life: A pilot study. Prehospital and Disaster Medicine, 27(1), 13-17.

Irwin, K., Hutton, A., \& Hill, P. (2015). Parental concern for their adolescent attending Schoolies: A literature review. Neonatal, Paediatric \& Child Health Nursing, 18(3), 2-7.

Iwamoto, D. K., \& Smiler, A. P. (2013). Alcohol makes you macho and helps you make friends: The role of masculine norms and peer pressure in adolescent boys' and girls' alcohol use. Substance Use \& Misuse, 48(5), 371-378.

Jiang, H., Callinan, S., Livingston, M., \& Room, R. (2016). Off-premise alcohol purchasing in Australia: Variations by age group, income level and annual amount purchased. Drug and Alcohol Review. doi:10.1111/dar.12402

Lam, T., Liang, W., Chikritzhs, T., \& Allsop, S. (2014). Alcohol and other drug use at school leavers' celebrations. Journal of Public Health, 36(3), 408-416. 
Lubman, D., Droste, N., Pennay, A., Hyder, S., \& Miller, P. (2014). High rates of alcohol consumption and related harm at Schoolies week: A portal study. Australian and New Zealand Journal of Public Health, 38(6), 536-541.

Mastroleo, N. R., Oakley, W. C., Eaton, E. M., \& Borsari, B. (2014). Response of heavydrinking voluntary and mandated college students to a peer-led brief motivational intervention addressing alcohol use. Journal of Substance Abuse Treatment, 47(5), 321-328.

Midford, R., Midford, S., \& Farringdon, F. (2007). School leaver (graduate) celebrations in Margaret River, Western Australia: A community approach to management. Substance Use \& Misuse, 42(12), 1915-1932.

Midford, R., Young, N., Farringdon, F., \& Bogaards, T. (2004). School leaver celebrations in Western Australia: A three-year intervention study. International Journal of Health Promotion and Education, 42(4), 100-108.

Mullan, B., Wong, C., Allom, V., \& Pack, S. L. (2011). The role of executive function in bridging the intention-behaviour gap for binge-drinking in university students. Addictive Behaviour, 36(10), 1023-1026.

National Health and Medical Research Council. (2009). Australian Guidelines to Reduce Health Risks from Drinking Alcohol. Retrieved from Canberra:

Pettigrew, S., Biagioni, N., Daube, M., Jones, S. C., Chikritzhs, T., \& Kirby, G. (2015). Understanding and addressing the Schoolies phenomenon. Australian New Zealand Journal of Public Health, 39(2), 135-140.

Pettigrew, S., Biagioni, N., \& Jongenelis, M. (2016). Anticipating and addressing eventspecific alcohol consumption among adolescents. BMC Public Health. doi:10.1186/s12889-016-3355-8.

Salom, C., George, J., Roach, K., \& Skinner, S. (2011). Final report of schoolies celebrations in Victoria 2009: Analysis, conclusions and recommendations. Melbourne, Victoria: Department of Health.

Voogt, C. V., Poelen, E. A., Kleinjan, M., Lemmers, L. A., \& Engels, R. C. (2013). The effectiveness of the 'What Do You Drink' web-based brief alcohol intervention in reducing heavy drinking among students: A two-arm parallel group randomized controlled trial. Alcohol and Alcoholism, 48(3), 312-321. 
1 Table 1.

2 Intended alcohol consumption, past drinking behaviour, binge drinking intentions, and

3 planned expenditure during Schoolies

\begin{tabular}{lccc}
\hline Variable & $\begin{array}{c}\text { Overall } \\
(n=187)\end{array}$ & $\begin{array}{c}\text { Males } \\
(n=72)\end{array}$ & $\begin{array}{c}\text { Females } \\
(n=115)\end{array}$ \\
& $\mathrm{M}(S D)$ & $\mathrm{M}(S D)$ & $\mathrm{M}(S D)$ \\
\hline Intended \# drinks & $8.18(11.17)$ & $11.51(14.99)^{* *}$ & $6.09(7.23)$ \\
Intending to binge drink (\%) & $56.1^{\dagger}$ & $65.3^{*}$ & $50.4^{\dagger}$ \\
Previous binge drinking behaviour & 43.7 & $59.2^{* * *}$ & 33.3 \\
Planned total expenditure & $\$ 965(748)$ & $\$ 1011(837)$ & $\$ 938(694)$ \\
Planned expenditure on alcohol & $\$ 131(139)$ & $\$ 159^{*}(156)$ & $\$ 115(125)$
\end{tabular}

$4 \quad$ a $\%$ at least once per month

$5 \quad *$ Significantly different from females at $p<.05$

$6 \quad * *$ Significantly different from females at $p<.01$

$7 \quad * *$ Significantly different from females at $p<.001$

$8 \quad$ Significantly different from previous drinking behaviour at $p<.01$ 